\title{
A novel stability-indicating method for known and unknown impurities profiling for diltiazem hydrochloride pharmaceutical dosage form (tablets)
}

Nitin Mahajan ${ }^{1^{*}} \mathbb{D}$, Suparna Deshmukh² and Mazahar Farooqui ${ }^{1}$

\begin{abstract}
Background: A novel gradient, high-sensitive and specific stability-indicating reverse-phase HPLC method was developed and validated for quantitative purpose of known, unknown and degradant impurities profiling for diltiazem hydrochloride tablets. The impurities were separated on the Zorbax RX C8 column (150 mm × $4.6 \mathrm{~mm}$, $5 \mu \mathrm{m}$ ) with mobile phase-A consisting of a mixture of $0.05 \mathrm{M}$ sodium dihydrogen phosphate monohydrate buffer $\mathrm{pH} 3.0$ and methanol in the ratio 800:200v/v and mobile phase-B consisting of acetonitrile with a flow rate of $1.0 \mathrm{~mL} \mathrm{~min}{ }^{-1}$. The column compartment was maintained at $35^{\circ} \mathrm{C}$, and the detection wavelength was $240 \mathrm{~nm}$. Diltiazem hydrochloride, its known impurities and unknown impurities have been well resolved from each other.

Results: The linearity of the method has been demonstrated across the concentration range of 0.18 to $5.65 \mu \mathrm{g} \mathrm{mL}{ }^{-1}$ for EP impurity-F with correlation coefficient $R^{2}$ greater than 0.99 . Recovery of method was proved from $L O Q$ to $150 \%$ for known and unknown impurities with respect to test concentration and found in between 80 and $120 \%$. Forced degradation study and specificity experiment results with mass balance proved the stability-indicating nature of the method and separated all known, unknown impurities and degradants from each other as well as from main drug component (diltiazem hydrochloride). The mass balance for stress study was found in between 95 and $105 \%$.
\end{abstract}

Conclusion: Newly developed analytical method was validated as per ICH Q2 (R1) guidelines "Validation of analytical procedure" and found linear, accurate, specific, robust and precise in the established working range.

Keywords: Diltiazem hydrochloride, Method development, Method validation, Impurities profiling, Stability indicating

\section{Background}

Diltiazem hydrochloride is chemically known as 3-(acetyloxy)-5-[2-(dimethylamino) ethyl]-2,3-dihydro2-(4-methoxyphenyl)-1, 5-benzothiazepin-4(5H)-one monohydrochloride (Fig. 1). Diltiazem hydrochloride is

*Correspondence: mahajan1925@gmail.com

1 Post Graduate and Research Centre, Department of Chemistry, Maulana Azad College of Arts, Science and Commerce, Aurangabad, Maharashtra 431001, India

Full list of author information is available at the end of the article a calcium channel-blocking agent, nondihydropyridine derivative [1].

Its medication was used to treat high blood pressure, angina and certain heart arrhythmias [2]. It may also be used in hyperthyroidism if beta blockers cannot be used [3]. The drug product is considered safe when the levels of impurities (known and unknown) are below the maximum permeability limits during the shelf-life study according to $\mathrm{ICH}$ guidelines $[4,5]$. The requirement of health agencies is that the impurities profiling analysis of drug substance and drug product during their shelf-life study was carried out using suitable validated analytical 


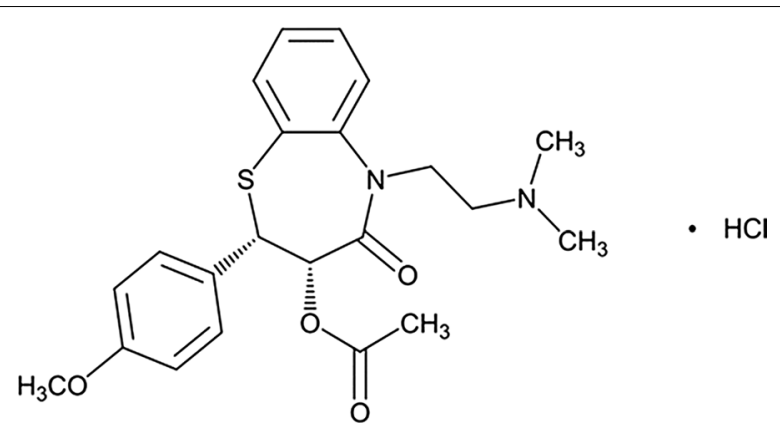

Fig. 1 Chemical structure of diltiazem hydrochloride

method [6-9]. The forced degradation study of drug product and drug substance is an important part in the development of analytical methods to demonstrate the stability-indicating power of the method. Forced degradation study of drug product and drug substance produces potential degradants impurities $[10,11]$. The drug product and drug substance are subjected to stress study such as oxidation, acid hydrolysis, alkali hydrolysis, photolytic degradation, thermal degradation and humidity degradation.

The force degradation study will help identify unknown potential degradants and provide information necessary for the stability of drug substances and pharmaceutical products. Therefore, the results of the diltiazem hydrochloride degradation study, which will provide information on the intrinsic stability of the drug product, are reported here.

The literature survey revealed that the several RPHPLC methods were reported for the determination of diltiazem hydrochloride alone [12-25] and in combination with other drugs or components [26-30].

Diltiazem hydrochloride drug substance (API) is cited in the British Pharmacopoeia [31] and European Pharmacopoeia [32] mentioned to monitor the following known impurities, i.e., impurities-A, B, C, D, E and F. US Pharmacopoeia is not discussed these impurities for diltiazem hydrochloride drug substance (API) [33]. For diltiazem hydrochloride pharmaceutical dosage form (tablets), no impurity profile method is available in British Pharmacopoeia and European Pharmacopoeia.

In US Pharmacopoeia for diltiazem hydrochloride pharmaceutical dosage form (tablets) monograph [34], impurities-A, B, C and D are mentioned, controlling these impurities under any unknown impurity, i.e., it indicates that these are process impurities and will not increase during stability. US Pharmacopoeia is not impurity-E and impurity-F profiling in pharmaceutical dosage form (tablets), while in European Pharmacopoeia for diltiazem hydrochloride drug substance (API) impurity-F is mentioned as degraded specified impurity and other impurities-A, B, C, D and E mentioned as unspecified impurity (controlled under any unknown impurity).

However, the comprehensive literature review found that very few methods were reported for the determination of related substances [35-37] and synthetic reagent [38] for diltiazem hydrochloride. The methods that have been reported for related substances by HPLC and HPLC-MS method [35] discussed characterization of impurities-A, B, E and F. An HPLC method for assay of diltiazem hydrochloride and its related substances (RS) in bulk drug and finished tablets was reported [36] without any comment on stability-indicating nature of the method and impurity profiling. The method was reported for related substances [37] having analysis run time about $90 \mathrm{~min}$, which is time-consuming in routine testing of samples, and another concern is system suitability testing of method involving preparation of resolution solution and standard solution in which each time impurities consumption involves which is not economically feasible. The method did not discuss European Pharmacopoeia impurity-C profiling and degradation kinetics.

Therefore, it is essential to develop a reverse-phase liquid chromatographic procedure for the impurities profiling and degradation kinetics of known European Pharmacopoeia impurities-A, B, C, E and F for diltiazem hydrochloride pharmaceutical dosage form (tablets) that will serve a reliable, accurate, sensitive, rugged, robust, stability indicating and economically feasible method.

By considering all the above information, the objective of method development and validation is to prove the specificity for impurities-A, B, C, E and F and validate the analytical method for EP impurity-F which is a specified degradation product as per European Pharmacopoeia for diltiazem hydrochloride pharmaceutical dosage form (tablets).

The chemical names of diltiazem hydrochloride and its impurities are shown in Table 1. The chemical structures of diltiazem hydrochloride and its impurities are shown in Figs. 1, 2, 3, 4, 5 and 6.

\section{Methods \\ Reagents and materials}

Marketed samples of diltiazem hydrochloride tablets were used for analytical method development and analytical method validation. The related substances (impurities-A, B, C, E and F) of diltiazem hydrochloride were procured from Olympus Chemical and Fertilizer, Mumbai (India). Sodium dihydrogen phosphate monohydrate, methanol and acetonitrile were obtained from Spectrochem Limited, and HPLC-grade water was obtained from Milli-Q purification system. $0.45-\mu \mathrm{m}$ PVDF filter was used of Merck, India make. 
Table 1 Chemical name of Diltiazem and its impurities

\begin{tabular}{|c|c|c|}
\hline Compound name & Chemical name & Molecular weight \\
\hline Diltiazem hydrochloride & $\begin{array}{l}\text { 3-(Acetyloxy)-5-[2-(dimethylamino) ethyl]-2, 3-dihydro-2-(4-methoxyphenyl)-1, 5-benzothiazepin -4(5H)- } \\
\text { one monohydrochloride }\end{array}$ & 450.98 \\
\hline Diltiazem EP impurity-A & $\begin{array}{l}\text { (2R,3S)-5-[2-(dimethylamino) ethyl]-2-(4-methoxyphenyl)-4-oxo-2,3,4,5-tetrahydro-1,5-benzothiazepine- } \\
\text { 3-yl acetate }\end{array}$ & 414.52 \\
\hline Diltiazem EP impurity-B & (2S,3S)-2-(4-methoxyphenyl)-4-oxo-2,3,4,5-tetrahydro-1, 5-benzothiazepine-3-yl acetate & 343.40 \\
\hline Diltiazem EP impurity-C & $\begin{array}{l}\text { (2S,3S)-5-[2-(dimethylamino)ethyl]-2-(4-hydroxyphenyl)-4-oxo-2,3,4,5-tetrahydro-1,5-benzothiazepin- } \\
\text { 3-yl acetate }\end{array}$ & 400.49 \\
\hline Diltiazem EP impurity-E & (2S,3S)-3-hydroxy-2-(4-methoxyphenyl)-2,3-dihydro-1,5- benzothiazepin-4(5H)-one & 301.36 \\
\hline Diltiazem EP impurity-F & $\begin{array}{l}\text { (2S,3S)-5-[2-(dimethylamino)ethyl]-3-hydroxy-2-(4-hydroxyphenyl)-2,3-dihydro-1,5-benzothiazepin- } \\
\text { 4(5H)-one }\end{array}$ & 372.5 \\
\hline
\end{tabular}

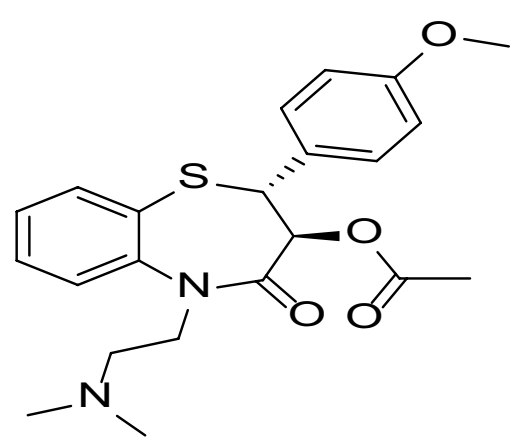

Fig. 2 Chemical structure of diltiazem EP impurity-A

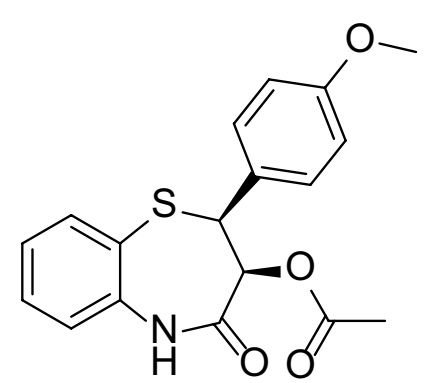

Fig. 3 Chemical structure of diltiazem EP impurity-B

\section{Instrumentation}

HPLC system (make: Waters) equipped with autosampler and quaternary gradient pump was used. The column compartment having temperature controlled and photodiode array detector (PDA) was used throughout the analysis. Chromatographic data were acquired using empower software.
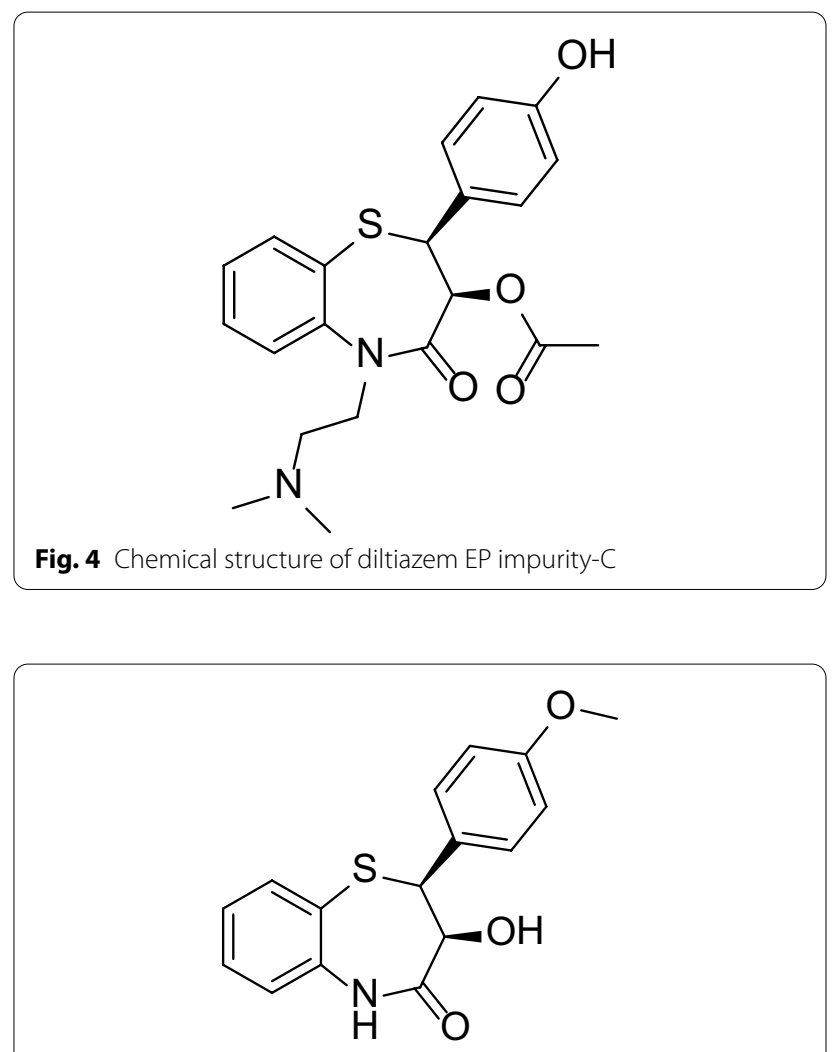

Fig. 5 Chemical structure of diltiazem EP impurity-E

\section{Chromatographic conditions}

A Zorbax RX C8 column (150 mm $\times 4.6 \mathrm{~mm}, 5 \mu \mathrm{m})$ (Agilent) was used as stationary phase maintained at $35{ }^{\circ} \mathrm{C}$. The mobile phase involved a variable composition of buffer and organic solvents, mobile phase-A (mixture of $0.05 \mathrm{M}$ sodium dihydrogen phosphate monohydrate buffer pH 3.0 and methanol in the ratio of 800:200 v/v, respectively) and mobile phase- $\mathrm{B}$ (containing acetonitrile). HPLC gradient program that was run is mentioned in Table 2. 


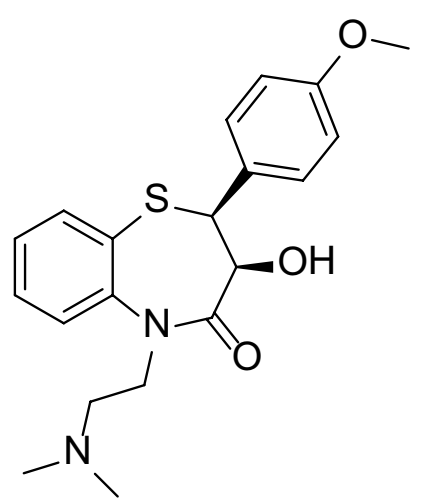

Fig. 6 Chemical structure of diltiazem EP impurity-F

Table 2 Mobile phase program for gradient elution

\begin{tabular}{llll}
\hline Time & Flow & Mobile phase-A (\%)) & $\begin{array}{l}\text { Mobile } \\
\text { phase-B } \\
\text { (\%) }\end{array}$ \\
\hline 0 & 1.0 & 90 & 10 \\
3 & 1.0 & 90 & 10 \\
13 & 1.0 & 75 & 25 \\
40 & 1.0 & 70 & 30 \\
41 & 1.0 & 90 & 10 \\
50 & 1.0 & 90 & 10 \\
\hline
\end{tabular}

\section{Diluent}

A mixture of $0.05 \mathrm{M}$ sodium dihydrogen phosphate monohydrate buffer $\mathrm{pH} 3.0$ and acetonitrile in the ratio of $60: 40 \% \mathrm{v} / \mathrm{v}$ was used as a diluent.

\section{Solution preparations}

\section{Standard solution}

Solution containing $2.4 \mu \mathrm{g} \mathrm{mL} \mathrm{m}^{-1}$ of diltiazem standard was prepared in diluent.

\section{Sample solution}

Twenty tablets were accurately weighed, the average weight was determined, the tablets were crushed, and the crushed powder equivalent to $120 \mathrm{mg}$ of diltiazem hydrochloride was transferred into a $100-\mathrm{mL}$ volumetric flask. Seventy milliliters of diluent was added, sonicated for about 15 min with intermittent shaking and then diluted with diluent. It was filtered through $0.45-\mu \mathrm{m}$ PVDF filter (concentration: $1200 \mu \mathrm{g} \mathrm{mL}^{-1}$ ).

\section{Forced degradation study}

Multiple stressed samples were prepared as indicated in the following. They were chromatographed along with a non-stressed sample. \%Degradation was calculated in terms of \% total impurities (known and unknown impurities) and \% degraded diltiazem peak along with mass balance reported in Table 3.

\section{Acid degradation}

Solution containing $1200 \mu \mathrm{g} \mathrm{mL} \mathrm{m}^{-1}$ of diltiazem hydrochloride was treated with $0.5 \mathrm{~N} \mathrm{HCl}$ in a water bath maintained at $80{ }^{\circ} \mathrm{C}$ for $2 \mathrm{~h}$. These solutions were neutralized as needed with $0.5 \mathrm{~N} \mathrm{NaOH}$.

\section{Base degradation}

Solution containing $1200 \mu \mathrm{g} \mathrm{mL} \mathrm{m}^{-1}$ of diltiazem hydrochloride was treated with $0.5 \mathrm{~N} \mathrm{NaOH}$ in a water bath maintained at $80{ }^{\circ} \mathrm{C}$ for $2 \mathrm{~h}$. These solutions were neutralized as needed with $0.5 \mathrm{~N} \mathrm{HCl}$.

\section{Peroxide degradation}

Solution containing $1200 \mu \mathrm{g} \mathrm{mL} \mathrm{m}^{-1}$ of diltiazem hydrochloride was treated with $5 \% \mathrm{w} / \mathrm{v}_{2} \mathrm{O}_{2}$. This treated sample solution was kept for $24 \mathrm{~h}$ at room temperature.

\section{Thermal degradation}

Crushed tablets powder equivalent to $120 \mathrm{mg}$ of diltiazem hydrochloride was transferred into a dry 100$\mathrm{mL}$ volumetric flask, and these samples were exposed at $80{ }^{\circ} \mathrm{C}$ in an oven for $48 \mathrm{~h}$.

Table 3 Degradation study data for diltiazem hydrochloride tablets

\begin{tabular}{|c|c|c|c|c|c|c|}
\hline Stress condition & $\begin{array}{l}\% \text { Total } \\
\text { Imp }\end{array}$ & $\begin{array}{l}\text { \% Assay } \\
\text { Diltiazem }\end{array}$ & $\begin{array}{l}\% \text { Mass } \\
\text { Balance }\end{array}$ & $\begin{array}{l}\text { Purity } \\
\text { Angle }\end{array}$ & $\begin{array}{l}\text { Purity } \\
\text { Threshold }\end{array}$ & $\begin{array}{l}\text { Purity } \\
\text { Flag }\end{array}$ \\
\hline $0.5 \mathrm{~N} \mathrm{HCl} / 80^{\circ} \mathrm{C}$ in water bath for $2 \mathrm{~h}$ & 7.21 & 90.17 & 97.4 & 0.070 & 0.278 & No \\
\hline $0.5 \mathrm{~N} \mathrm{NaOH} / 80^{\circ} \mathrm{C}$ in water bath for $2 \mathrm{~h}$ & 6.88 & 90.92 & 97.8 & 0.068 & 0.283 & No \\
\hline $5 \% \mathrm{H}_{2} \mathrm{O}_{2}$ for $24 \mathrm{~h}$ at room temperature & 3.45 & 97.45 & 100.9 & 0.051 & 0.243 & No \\
\hline Humidity/ $\left(40^{\circ} \mathrm{C} / 75 \% \mathrm{RH}\right)$ for 5 days & 0.28 & 99.84 & 100.1 & 0.546 & 2.455 & No \\
\hline Thermal/ $80^{\circ} \mathrm{C} / 48 \mathrm{~h}$ & 0.32 & 99.83 & 100.2 & 0.594 & 2.427 & No \\
\hline Photolytic/250 Wh/m²/1.2 million Lux hours & 0.26 & 99.86 & 100.1 & 0.586 & 2.444 & No \\
\hline
\end{tabular}

Imp., impurity 


\section{Photolytic degradation}

Crushed tablets powdered are directly exposed in a photolytic chamber for 1.2 million Lux hours with energy not less than $200 \mathrm{Wh} / \mathrm{m}^{2}$.

\section{Humidity degradation}

Crushed tablets powder equivalent to $120 \mathrm{mg}$ of diltiazem hydrochloride was transferred into a dry 100$\mathrm{mL}$ volumetric flask, and these tablets were exposed at $40{ }^{\circ} \mathrm{C} / 75 \% \mathrm{RH}$ for 5 days in a humidity chamber.

\section{Results}

\section{Method validation}

The developed reverse-phase HPLC analytical method was validated according to $\mathrm{ICH}$ guidelines with respect to specificity, accuracy, precision (method precision and intermediate precision), linearity, range and robustness.

Additional experiment of filter compatibility study conducted to prove the analysis results is not affected by the use of PVDF or nylon filter.

\section{System suitability}

The system suitability of test method was evaluated by injecting single injection of blank (diluent) solution and standard solution in six times.

USP plate count, USP tailing and \%RSD of diltiazem peak area from six replicate injections of standard solution were evaluated.

The acceptance criteria defined from six replicate injections of standard solution are \%RSD of diltiazem peak area should not be more than 5.0\%, USP tailing for diltiazem peak should not be more than 2.0 and USP plate count for diltiazem peak should not be less than 5000 .

\section{Specificity}

Peak purity results for the analyte in force degradation studies were determined with the PDA detector [39, 40] under optimized chromatographic conditions considered homogeneous (purity angle $<$ purity threshold), indicating that no additional peaks were co-eluting with the analyte (diltiazem and its known impurity) and the specificity of the method. Resolution was achieved for all known, unknown impurities and degradants.

\section{Stability of drug substance in analytical solution}

The stability of the drug in the analytical solution was verified by preparing the sample solution as per the method and injecting at regular time intervals into proposed method at $7{ }^{\circ} \mathrm{C}$ temperature. On verifying the formation of additional peaks, it was found that no additional peaks were formed and there was no increase in the present known and unknown impurities by $0.04 \%$ level from its initial level to till $50 \mathrm{~h}$, indicating that the sample solution is stable for about $50 \mathrm{~h}$ at $7{ }^{\circ} \mathrm{C}$.

The stability of the standard solution was assessed by injecting the standard solution at various time intervals up to $59 \mathrm{~h}$ into the proposed method at $7{ }^{\circ} \mathrm{C}$. \%RSD of the diltiazem peak area was monitored from its initial level to $59 \mathrm{~h}$ and found less than $5.0 \%$ from its initial level, indicating that the standard solution is stable for about $59 \mathrm{~h}$ at $7^{\circ} \mathrm{C}$.

\section{Filter paper compatibility study}

Filter compatibility study was performed by analysis of duplicate preparation of spike sample (spiked with impurity-F) filtered with 0.45- $\mu \mathrm{m}$ PVDF filter and 0.45$\mu \mathrm{m}$ nylon filter. Results were compared with centrifuged (unfiltered) spiked sample results. \% absolute difference of $\% \mathrm{w} / \mathrm{w}$ impurity content and total impurities were evaluated. On verifying that the $\%$ absolute difference should not be more than $0.02 \%$ for individual impurity, $\%$ absolute difference should not be more than $0.04 \%$ for total impurities compared and no additional peak should be formed above limit of quantification level with unfiltered spike sample results. Filter compatibility results are reported in Table 4

\section{Linearity and range}

The test concentration for diltiazem hydrochloride is $1200 \mathrm{mg} \mathrm{mL}{ }^{-1}$. Consider the impurity tolerance limit level $0.3 \%$ with respect to test concentration of diltiazem hydrochloride. The response function was determined

Table 4 Filter paper compatibility results

\begin{tabular}{|c|c|c|c|c|}
\hline Filter paper & $\begin{array}{l}\text { Prep } \\
\text { No. }\end{array}$ & $\begin{array}{l}\text { Imp-F } \\
(\% w / w)\end{array}$ & $\begin{array}{l}\text { SMU Imp } \\
(\% w / w)\end{array}$ & $\begin{array}{l}\text { Total Imp } \\
(\% \mathrm{w} / \mathrm{w})\end{array}$ \\
\hline Centrifuge & 1 & 0.35 & 0.02 & 0.41 \\
\hline Centrifuge & 2 & 0.35 & 0.02 & 0.41 \\
\hline $0.45-\mu m$ PVDF & 1 & 0.35 & 0.02 & 0.41 \\
\hline $0.45-\mu \mathrm{m}$ PVDF & 2 & 0.35 & 0.02 & 0.41 \\
\hline 0.45-um Nylon & 1 & 0.35 & 0.02 & 0.41 \\
\hline 0.45- $\mu$ m Nylon & 2 & 0.35 & 0.02 & 0.41 \\
\hline \multicolumn{5}{|c|}{$\%$ Absolute difference $(\% w / w)$} \\
\hline Centrifuge & 1 & 0.00 & 0.00 & 0.00 \\
\hline Centrifuge & 2 & 0.00 & 0.00 & 0.00 \\
\hline $0.45-\mu \mathrm{m}$ PVDF & 1 & 0.00 & 0.00 & 0.00 \\
\hline $0.45-\mu \mathrm{m}$ PVDF & 2 & 0.00 & 0.00 & 0.00 \\
\hline 0.45-um Nylon & 1 & 0.00 & 0.00 & 0.00 \\
\hline 0.45- $\mu \mathrm{m}$ Nylon & 2 & 0.00 & 0.00 & 0.00 \\
\hline
\end{tabular}

Pre., preparation; SMU, single max unknown; Imp., impurity 
Table 5 Regression statistics of linearity experimental results

\begin{tabular}{llllrr}
\hline Compound & $\begin{array}{l}\text { Concentration } \\
\boldsymbol{\mu g} \mathbf{~ m L}^{-1}\end{array}$ & $\begin{array}{l}\text { Multiple } \\
\mathbf{R}\end{array}$ & Regression equation & F value & $\boldsymbol{P}$ value \\
\hline Diltiazem hydrochloride & 0.12 to 4.84 & 1.000 & $y=63810.96 x+1124.7$ & 11,398 & $<0.05$ \\
EP Imp.-F & 0.18 to 5.65 & 0.999 & $y=78198.34 x+178.13$ & 29,206 & $<0.05$ \\
\hline
\end{tabular}

Table 6 Limit of quantification, detection and response factor (LOQ, LOD and RF)

\begin{tabular}{|c|c|c|c|c|c|}
\hline \multirow[t]{2}{*}{ Compound } & \multicolumn{2}{|l|}{ LOQ } & \multicolumn{2}{|l|}{ LOD } & \multirow[t]{2}{*}{$\mathrm{RF}$} \\
\hline & $\mu \mathrm{g} \mathrm{mL}^{-1}$ & $\% w / w^{a}$ & $\mu \mathrm{g} \mathrm{mL}^{-1}$ & $\% w / w^{a}$ & \\
\hline EP impurity-F & 0.18 & 0.015 & 0.06 & 0.005 & 0.82 \\
\hline Diltiazem hydrochloride & 0.12 & 0.01 & 0.04 & 0.003 & 1.00 \\
\hline
\end{tabular}

a $\% w / w$ calculated with respect to sample concentration $\left(1200 \mu \mathrm{g} \mathrm{mL}^{-1)}\right.$

by preparing a standard solution of diltiazem hydrochloride and impurity- $\mathrm{F}$ at various concentration levels ranging from the lower limit of quantification to $150 \%$ of the impurity limit level.

The linearity graph of peak responses of the analytes relative to their corresponding concentrations was determined and found linear. The square of the residuals graph shows random pattern and passes the normal distribution test $(\mathrm{p}<0.05)$ which prove the method is linear in the working concentration range.

The regression statistics of linearity experimental results are shown in Table 5.

\section{Determination of limit of quantification and detection (LOQ and LOD)}

The linearity carried out as indicated above was used for the determination of limit of quantification (LOQ), limit of detection (LOD) and residual standard deviation $(\sigma)$.

And visual method based on signal-to-noise ratio was used for prediction of LOQ and LOD.

Precision was established for predicted level of LOQ and LOD. The LOQ and LOD results are given in Table 6.

$$
\begin{aligned}
& \mathrm{LOQ}=10 \sigma / \mathrm{s} \\
& \mathrm{LOD}=3.3 \sigma / \mathrm{s}
\end{aligned}
$$

where $\sigma=$ residual standard deviation of response and $s=$ slope of the calibration curve.

\section{Determination of response factor (RF) with linear calibration curve}

Calibration curves for all components were constructed using the peak areas and analyte concentrations in the range reported in Table 5 by linear regression analysis. The linear regression equation containing the slope for
Table 7 Recovery for diltiazem hydrochloride

\begin{tabular}{lllll}
\hline Levels & Preparation & \% Recovery & Mean & \%RSD \\
\hline LOQ & 1 & 113.0 & 112.3 & 0.5 \\
& 2 & 112.0 & & \\
\multirow{2}{*}{$50 \%$} & 3 & 112.0 & & \\
& 1 & 98.0 & 97.3 & 0.6 \\
& 2 & 97.0 & & \\
$100 \%$ & 3 & 97.0 & & \\
& 1 & 98.5 & 98.5 & 0.0 \\
& 2 & 98.5 & & \\
$150 \%$ & 3 & 98.5 & & \\
& 1 & 98.0 & 98.1 & 0.2 \\
& 2 & 98.3 & & \\
\hline
\end{tabular}

all components is summarized in Table 5 . The response factor (RF) was determined as the ratio of slope of the regression line of main drug component (diltiazem hydrochloride) to that for impurity and is listed in Table 6.

\section{Accuracy}

Accuracy was assessed by the simultaneous determination of analytes in solution prepared by standard addition method. The experiment was conducted by adding the known amount of impurity (impurity-F) in the test sample by considering the tolerance level, i.e., $0.3 \% \mathrm{w} / \mathrm{w}$ and diltiazem hydrochloride in the placebo (excipient) corresponding to four concentration levels at LOQ, 50\%, 100\% and $150 \%$ by considering the tolerance level, i.e., $0.3 \% \mathrm{w} / \mathrm{w}$ with respect to test sample concentration.

Triplicate sample at each level was prepared. The quantification of added impurity-F and diltiazem hydrochloride (\%weight/weight) was calculated as per method by applying RF (response factor) of impurity.

The experimental finding has shown that approximately $80 \%$ to $120 \%$ of the recovery was obtained for the related compounds studied and \%RSD for triplicate preparation of recovery results found less than $10 \%$.

Therefore, based on the recovery experimental (Tables 7 and 8 ) the estimation of related substances 
Table 8 Recovery for diltiazem EP impurity-F

\begin{tabular}{llrcc}
\hline Levels & Preparation & \% Recovery & Mean & \%RSD \\
\hline LOQ & 1 & 100.0 & 99.6 & 1.4 \\
& 2 & 98.0 & & \\
& 3 & 100.7 & & \\
$50 \%$ & 1 & 99.3 & 100.0 & 0.7 \\
& 2 & 100.0 & & \\
& 3 & 100.7 & & \\
$100 \%$ & 1 & 97.7 & 98.1 & 0.5 \\
& 2 & 98.0 & & \\
& 3 & 98.7 & & \\
$150 \%$ & 1 & 98.2 & 98.2 & 0.2 \\
& 2 & 98.4 & & \\
& 3 & 98.0 & & \\
\hline
\end{tabular}

that are prescribed in this report was shown to be accurate for its intended purpose and is adequate for routine analysis.

\section{Method precision and ruggedness}

According to the ICH (International Conference on Harmonization of Technical Requirements for Registration of Pharmaceuticals for Human Use), ruggedness is considered as the method reproducibility and intermediate precision.

Method precision was evaluated by preparing six spike samples by spiking the known impurity (Impurity-F) at $0.3 \% \mathrm{w} / \mathrm{w}$ level with respect to test concentration $\left(1200 \mu \mathrm{g} \mathrm{mL}^{-1}\right)$.

Intermediate precision was evaluated by different analysts on different HPLC systems on different columns on different days. Experiment was conducted same as method precision experiment by spiking the known impurities (impurity-F) at $0.3 \% \mathrm{w} / \mathrm{w}$ level with respect to test concentration.

Results (\%w/w) were calculated for known, unknown and total impurities for method precision and intermediate precision experiment. \%RSD was calculated for $(\% \mathrm{w} / \mathrm{w})$ known, unknown and total impurities and found less than $10 \%$

Overall \%RSD for (\%w/w) known, unknown and total impurities was calculated for method precision and intermediate precision experiment results $(n=12$ results, six from method precision and six from intermediate precision) and found less than $10.0 \%$

The results for method precision and intermediate precision listed in Tables 9 and 10 reveal that the method has good reproducibility with acceptable precision.
Table 9 Comparison of method precision and intermediate precision results

\begin{tabular}{lllll}
\hline Name & $\begin{array}{l}\text { MP } \\
\text { Imp-F }\end{array}$ & $\begin{array}{l}\text { IP } \\
\text { Imp-F }\end{array}$ & $\begin{array}{l}\text { MP } \\
\text { Unknown } \\
\text { Imp. (SM) }\end{array}$ & $\begin{array}{l}\text { IP } \\
\text { Unknown } \\
\text { Imp. (SM) }\end{array}$ \\
\hline Spike sample-1 & 0.31 & 0.29 & 0.02 & 0.02 \\
Spike sample-2 & 0.31 & 0.30 & 0.02 & 0.02 \\
Spike sample-3 & 0.31 & 0.30 & 0.02 & 0.02 \\
Spike sampel-4 & 0.31 & 0.30 & 0.02 & 0.02 \\
Spike sample-5 & 0.30 & 0.30 & 0.02 & 0.02 \\
Spike sample-6 & 0.30 & 0.30 & 0.02 & 0.02 \\
Mean & 0.31 & 0.30 & 0.02 & 0.02 \\
\%RSD & 1.68 & 1.37 & 0.0 & 0.0 \\
Overall Mean & 030 & & 0.02 & \\
Overall \%RSD & 2.1 & & 0.0 & \\
\hline
\end{tabular}

MP, method precision; IP, intermediate precision; SM, single max

\section{Robustness}

The robustness of the method has been demonstrated by establishing the system suitability parameter by change in flow rate by $\pm 0.1 \mathrm{~mL} \mathrm{~min}{ }^{-1}$, change in column oven temperature by $\pm 5{ }^{\circ} \mathrm{C}$, change in organic composition of mobile phase-A by $\pm 2 \%$ absolute and change in wavelength by $\pm 5 \mathrm{~nm}$. The method was found robust by deliberate change in chromatographic conditions as mentioned above.

\section{Discussion}

The probable impurities of diltiazem hydrochloride are very similar to respective structure of drug substances. Diltiazem hydrochloride is freely soluble in water and methanol and practically soluble in acetonitrile [37].

The molecular structure (Figs. 1, 2, 3, 4, 5 and 6) shows that the diltiazem hydrochloride and its related

Table 10 Comparison of method precisions and intermediate precision results

\begin{tabular}{lll}
\hline Name & $\begin{array}{l}\text { MP } \\
\text { Total impurities }\end{array}$ & $\begin{array}{l}\text { IP } \\
\text { Total impurities }\end{array}$ \\
\hline Spike sample-1 & 0.37 & 0.35 \\
Spike sample-2 & 0.37 & 0.36 \\
Spike sample-3 & 0.37 & 0.36 \\
Spike sampel-4 & 0.37 & 0.36 \\
Spike sample-5 & 0.36 & 0.36 \\
Spike sample-6 & 0.36 & 0.36 \\
Mean & 0.37 & 0.36 \\
\%RSD & 1.41 & 1.14 \\
Overall Mean & 0.36 & \\
Overall \%RSD & 1.7 & \\
\hline
\end{tabular}

MP, method precision; IP, intermediate precision 


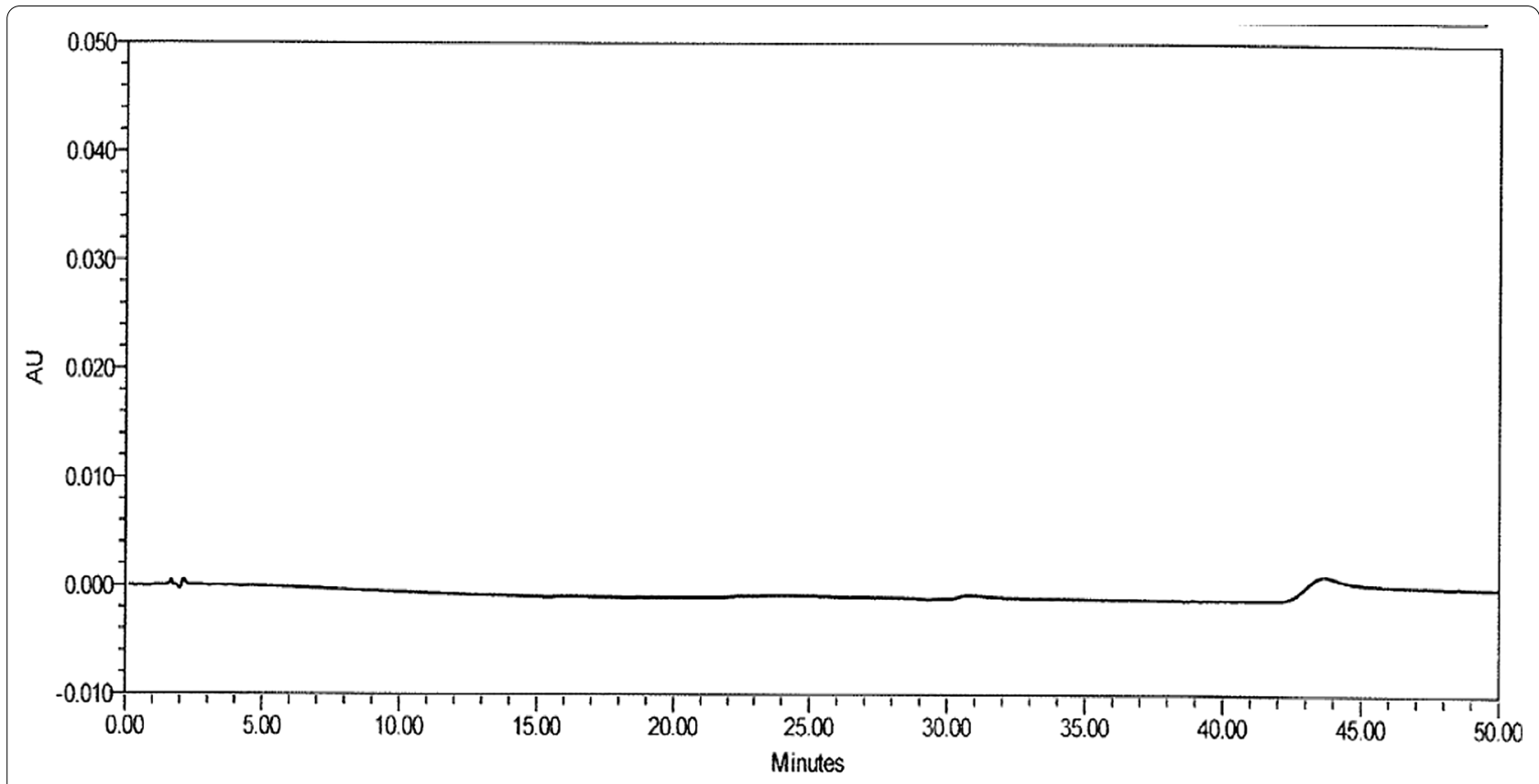

Fig. 7 Typical HPLC chromatogram of blank

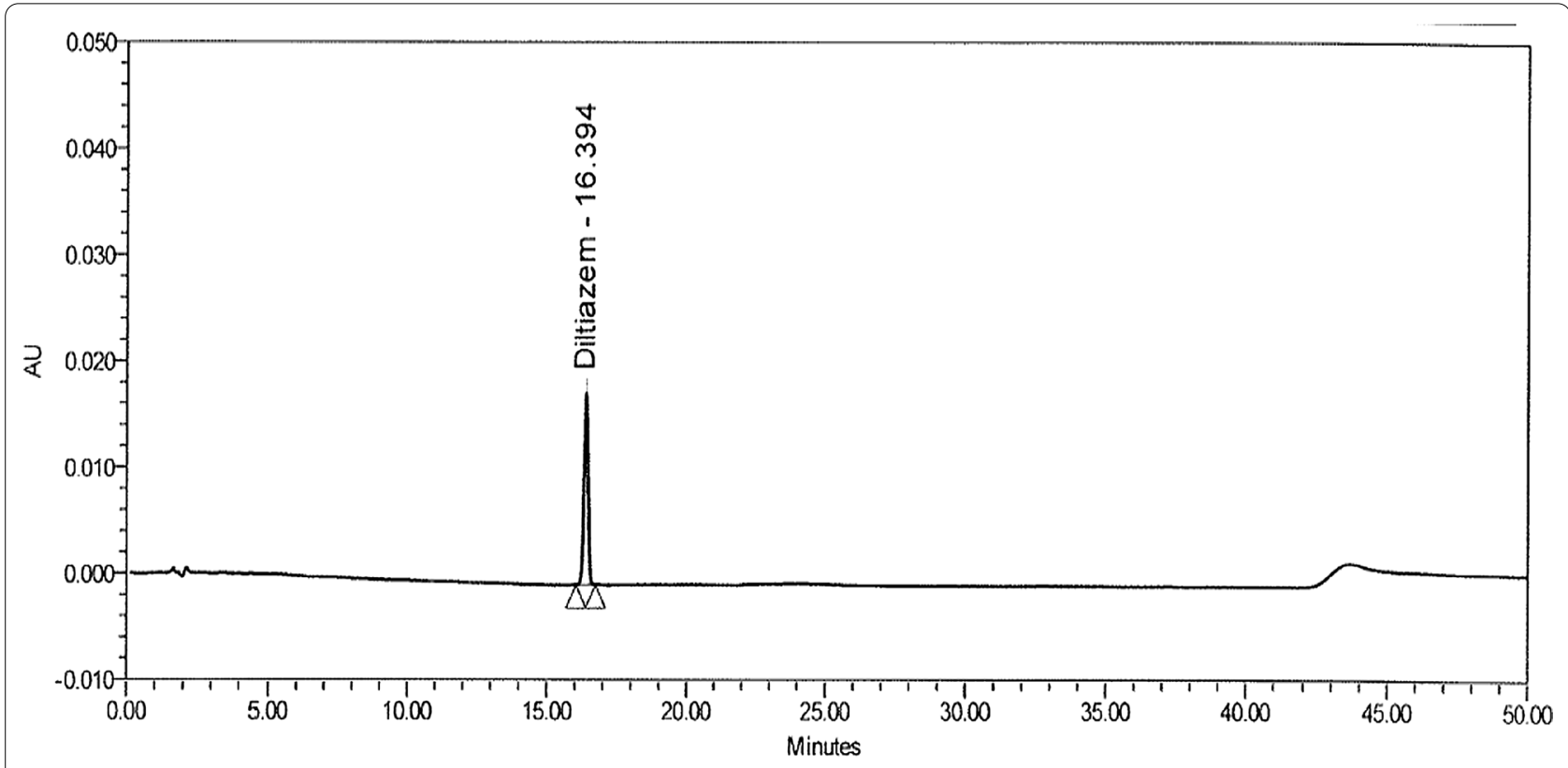

Fig. 8 Typical HPLC chromatogram of standard

compounds (impurity-A, impurity-B, impurity-C, impurity-E and impurity-F) are polar in nature due to the presence of amine group $(-\mathrm{NH})$.

The objective of the method development is to separate the all known, unknown impurities and degradants among from each other as well as from main drug substances with short run time of analysis. Different columns consist of different stationary phases $\left(\mathrm{RP}-\mathrm{C}_{8}\right.$ and $\left.\mathrm{RP}-\mathrm{C}_{18}\right)$, and different particle sizes of the column $(3 \mu \mathrm{m}$ and $5 \mu \mathrm{m})$ were also tested.

Considering diltiazem hydrochloride and their known related impurities polar in nature, the following mobile 


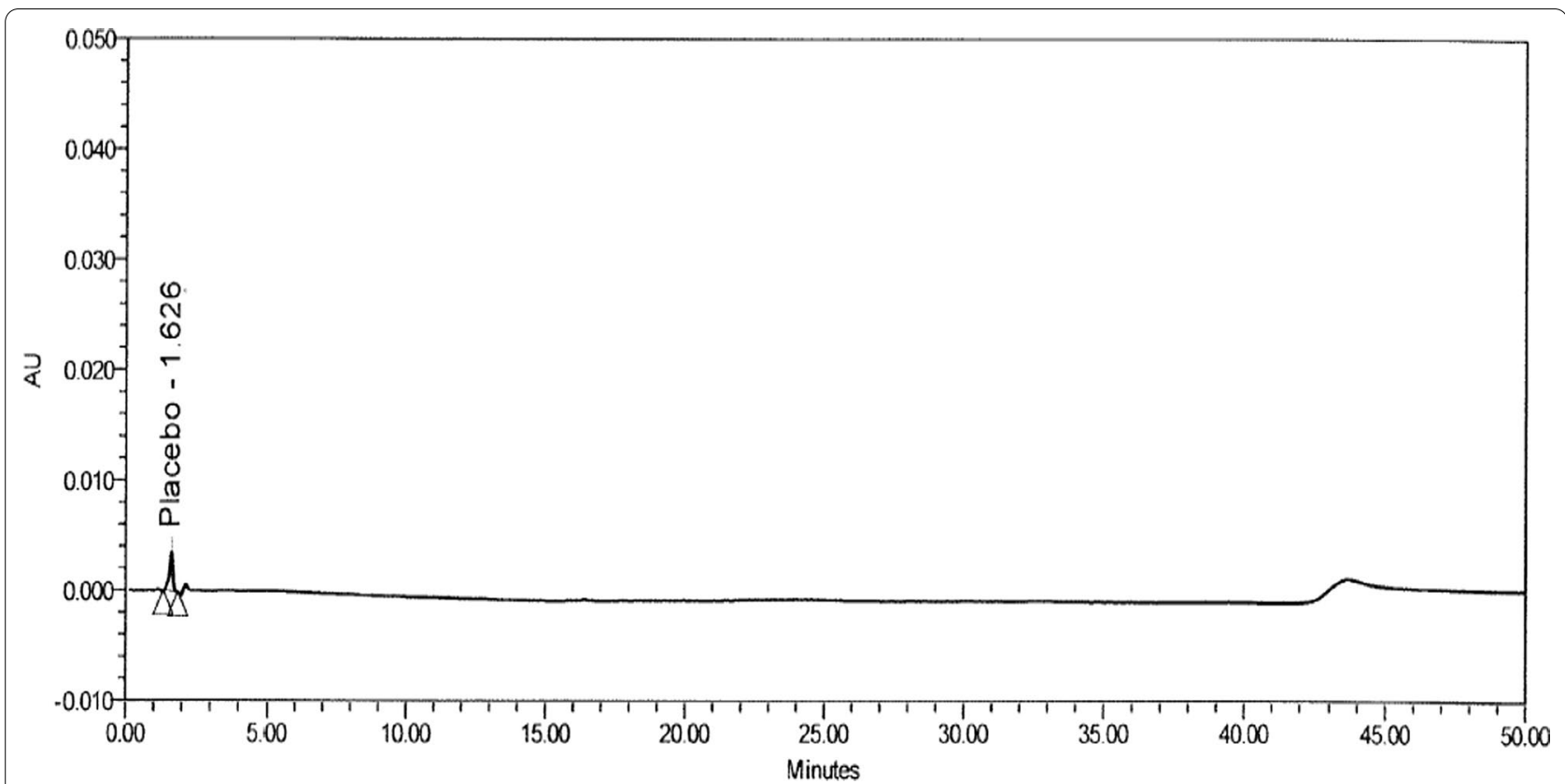

Fig. 9 Typical HPLC chromatogram of placebo solution

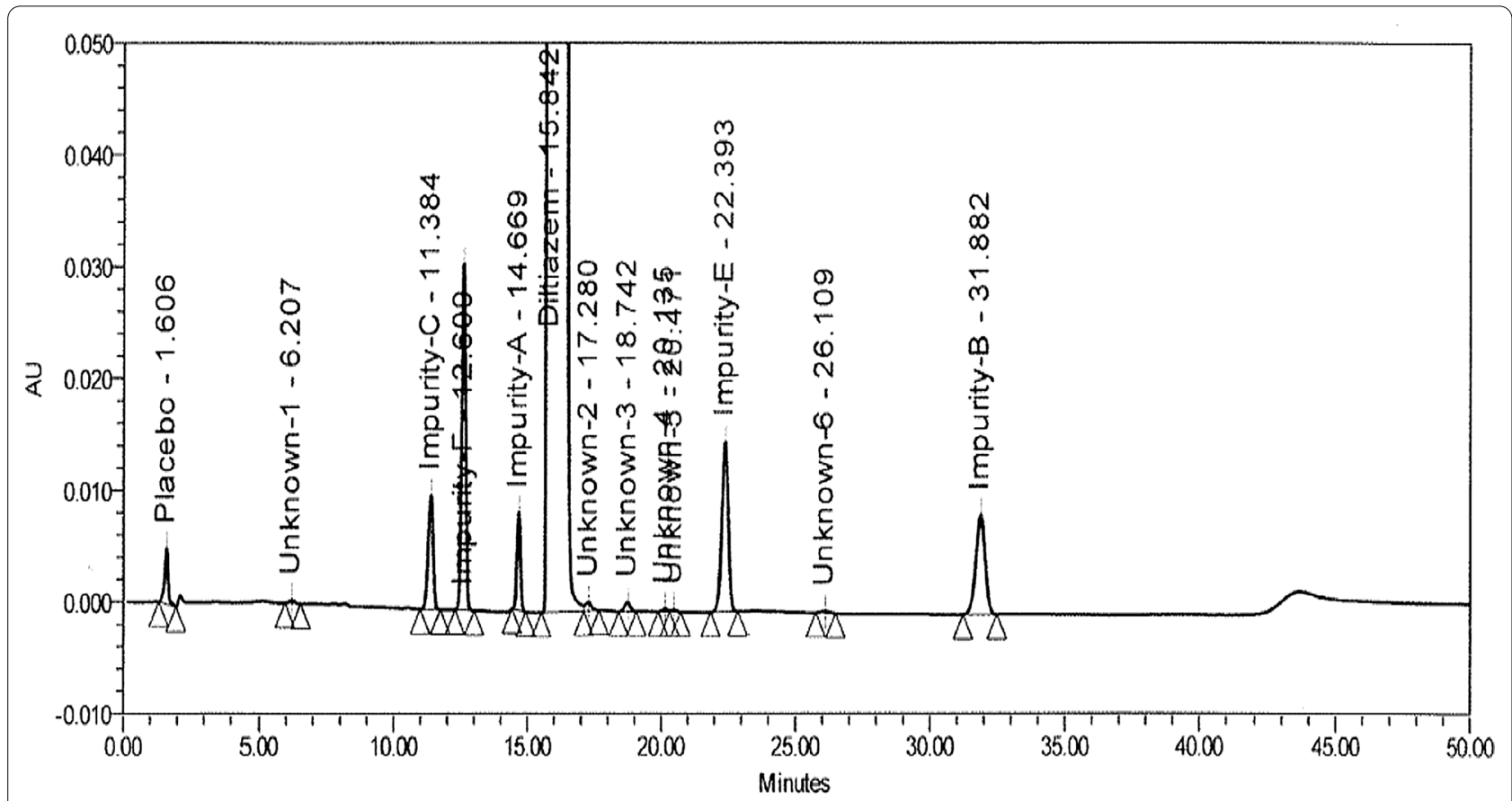

Fig. 10 Typical HPLC chromatogram of spike sample 


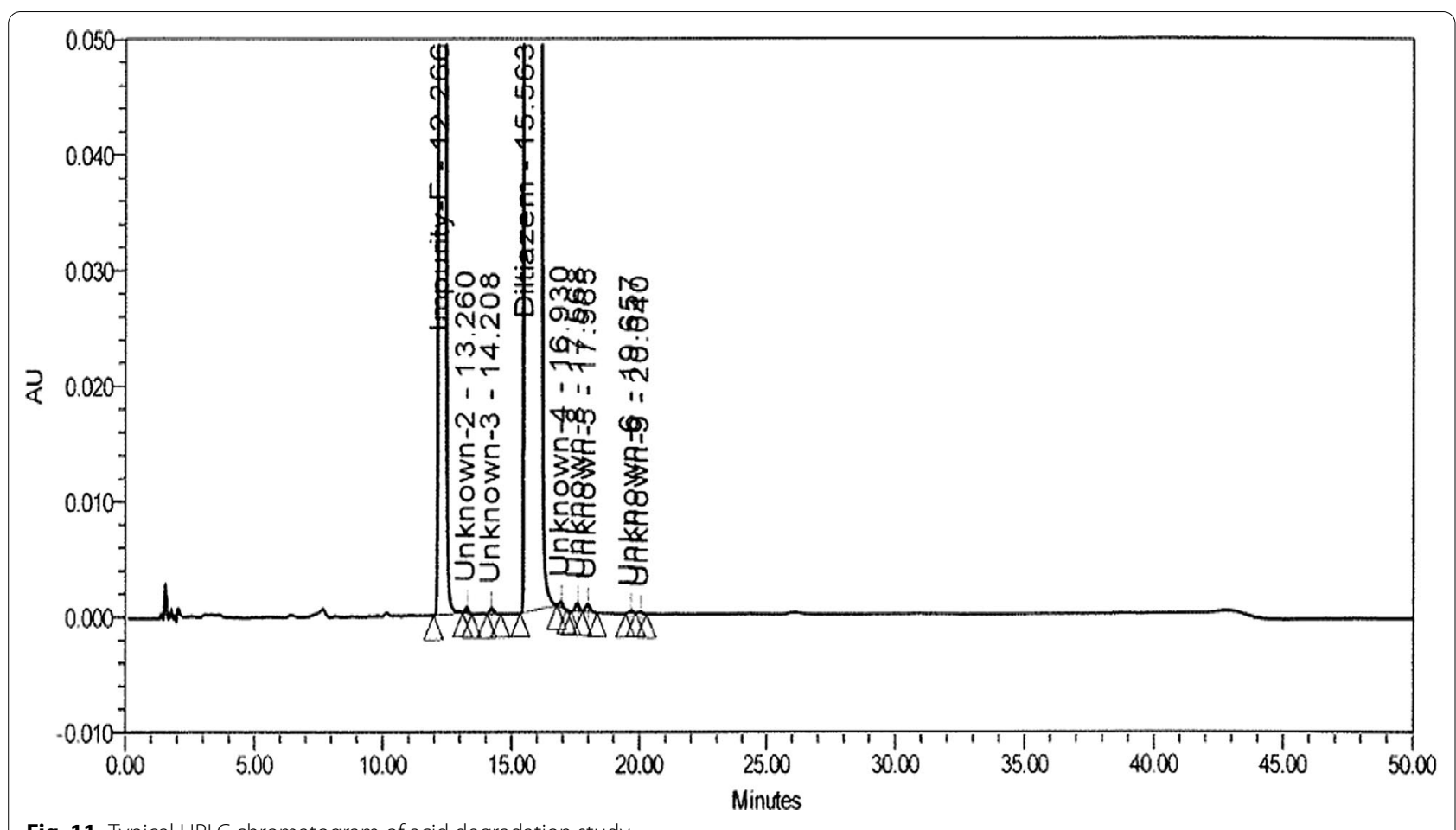

Fig. 11 Typical HPLC chromatogram of acid degradation study

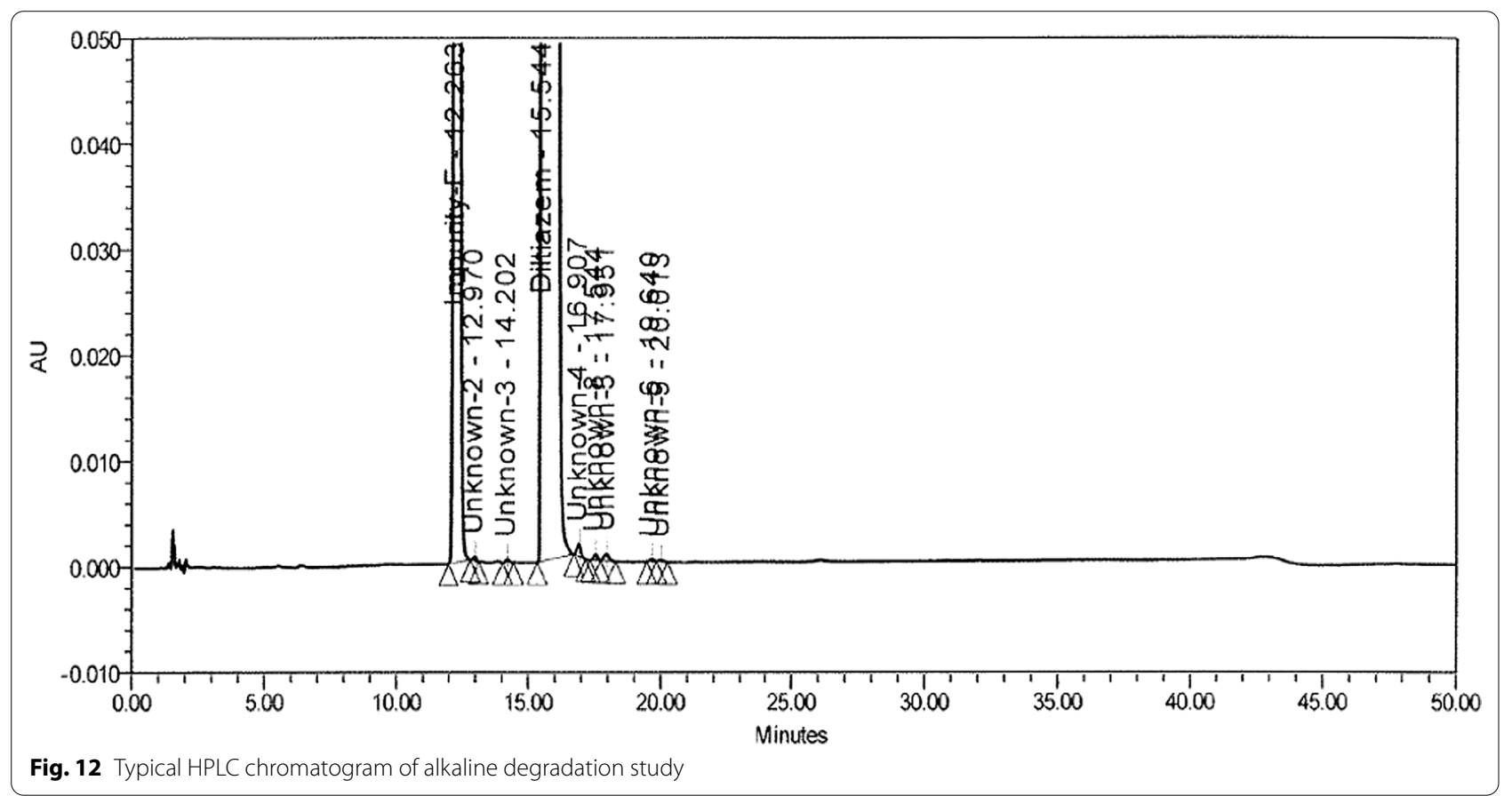




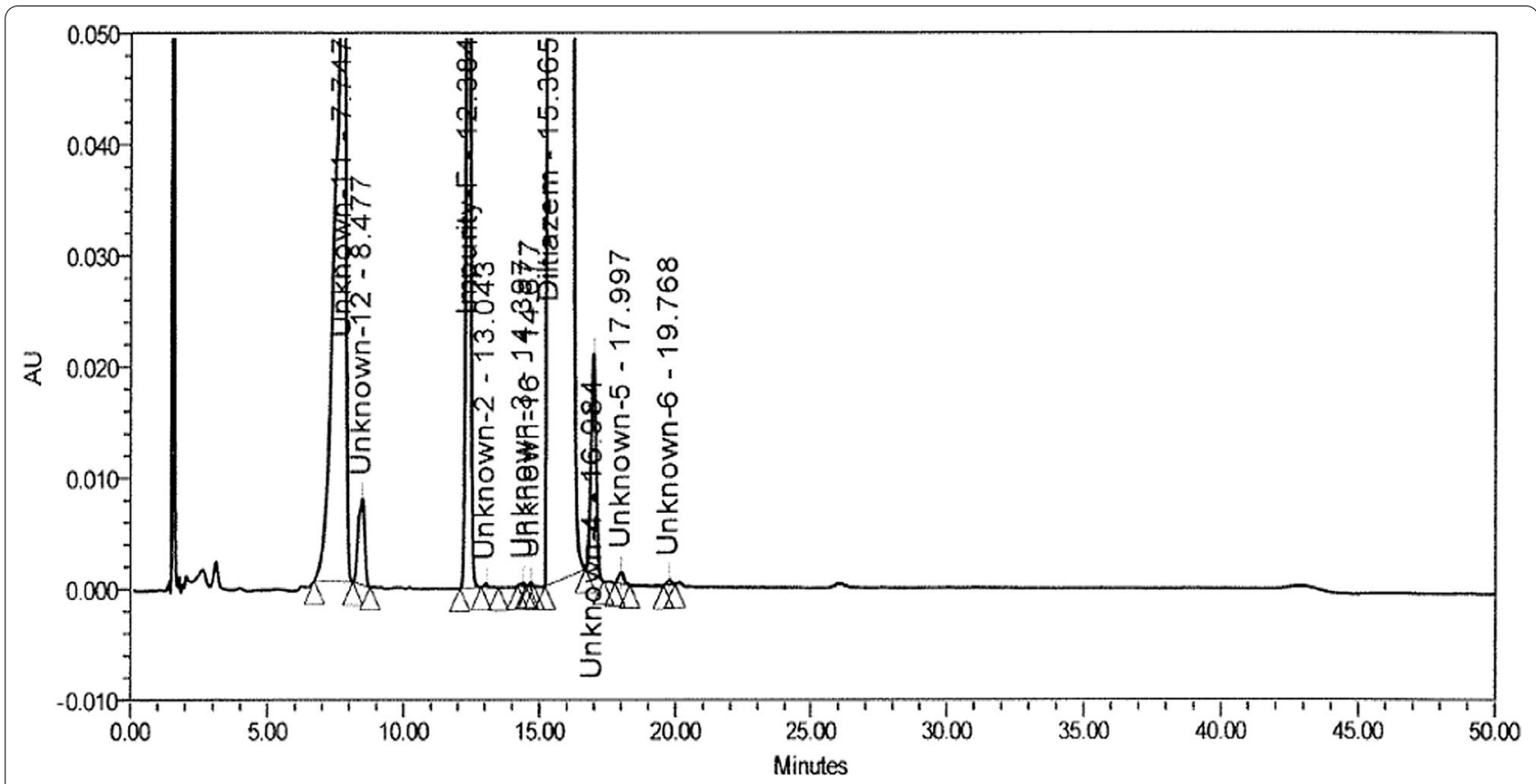

Fig. 13 Typical HPLC chromatogram of oxidative degradation study

phases with gradient elution attempts were done to separate all the impurities which are present and generated during stress studies:

(a) Trifluoroacetic acid buffer with methanol, (b) trifluoroacetic acid buffer with acetonitrile, (c) potassium dihydrogen phosphate buffer with methanol, (d) potassium dihydrogen buffer with acetonitrile, (e) sodium dihydrogen phosphate monohydrate buffer with methanol and (f) sodium dihydrogen phosphate monohydrate buffer with acetonitrile.

The $\mathrm{pH}$ of the above buffers varies from 2.8 to 4.0 during method development trials.

\section{Selection of stationary phase: [7]}

The poor resolution between diltiazem hydrochloride and diltiazem hydrochloride impurities (impurities-A, $\mathrm{B}, \mathrm{C}, \mathrm{E}$ and F) as well as broad peak shape for diltiazem hydrochloride observed, early elution (in void volume) of impurities implies that $\mathrm{C}_{18}$ stationary phase is not suitable for this application. Hence, $\mathrm{C}_{8}$ stationary phase was chosen to improve resolution among the peaks and peak shape for diltiazem hydrochloride. The peak shape for diltiazem hydrochloride and resolution among all components improved with a Zorbax RX C8 column $(150 \mathrm{~mm} \times 4.6 \mathrm{~mm}, 5 \mu \mathrm{m})$.

\section{Selection of mobile phase: [7]}

Resolution among the known related impurities and unknown impurities of diltiazem hydrochloride was found poor using mobile phase with trifluoroacetic acetic acid buffer and potassium dihydrogen phosphate buffer. Broad peak shape for diltiazem hydrochloride and nonGaussian peak shape were observed impurities with the use of the above buffer. The use of combination of sodium dihydrogen phosphate monohydrate buffer $\mathrm{pH}$ 3.0 with methanol gives the better resolution among the impurities and Gaussian peak shape for diltiazem and all impurities.

After an extensive study, the method has been finalized on a Zorbax RX C8 column $(150 \mathrm{~mm} \times 4.6 \mathrm{~mm}, 5 \mu \mathrm{m})$ using variable composition of mobile phase-A (mixture of $0.05 \mathrm{M}$ sodium dihydrogen phosphate monohydrate buffer pH3.0 with methanol in the ratio 800:200 v/v, respectively) and mobile phase- $\mathrm{B}$ containing acetonitrile.

The mobile phase was at a flow rate of $1.0 \mathrm{~mL} \mathrm{~min}{ }^{-1}$, and column compartment temperature was kept at 35 ${ }^{\circ} \mathrm{C}$. The detector response for all the components found maximum at $240 \mathrm{~nm}$; hence, the typical chromatogram was recorded at this wavelength. The typical HPLC chromatograms for blank, standard, placebo and spike sample are represented in Figs. 7, 8, 9 and 10, respectively.

The typical HPLC chromatograms of acidic, alkaline and photolytic stressed conditions (force degradation) sample are represented in Figs. 11, 12 and 13, respectiv ely.

In acid degradation, alkaline degradation (Figs. 11 and 12 , respectively), it was observed that the known impurity- $\mathrm{F}$ found major degradation impurity. In oxidative 
degradation (Fig. 13), unknown impurity at 0.55 RRT found major degradation impurity and known impurity$\mathrm{F}$ increased $(1.05 \% \mathrm{w} / \mathrm{w})$ significantly from its initial level $(0.04 \% \mathrm{w} / \mathrm{w})$.

\section{Conclusion}

Analytical method validation experiment results revealed that the newly developed analytical method is linear, accurate, specific and precise in the established working concentration range. Forced degradation study and specificity experiment results with mass balance prove the stability-indicating nature of the method and separate all known, unknown impurities and degradants from each other as well as from main drug component (diltiazem hydrochloride).

The method is robust to change in flow rate, column oven temperature, change in wavelength and change in organic composition of mobile phase.

Hence, this novel analytical method can be intended for routine analysis as well as to monitor the known, unknown and degradant profile of diltiazem hydrochloride pharmaceutical dosage form (tablets).

\section{Abbreviations}

LOQ: Limit of Quantification; LOD: Limit of Detection; RRT: Relative Retention Time; EP: European Pharmacopoeia; HPLC: High-Performance Chromatography; MS: Mass Spectrophotometer; RH: Relative Humidity.

\section{Acknowledgements}

The authors thank Management of Maulana Azad College of Arts, Science and Commerce for providing excellent research facilities.

\section{Authors' contributions}

NM conceptualized, designed and executed the current research work. SD and MF supervised the work. All the authors read and approved the final manuscript.

\section{Funding}

Not applicable.

\section{Availability of data and materials}

All the data and material will be available upon request.

\section{Declarations}

Ethics approval and consent to participate

Not applicable.

\section{Consent for publication \\ Not applicable.}

\section{Competing interests}

The authors declare that they have no competing interest.

\section{Author details}

${ }^{1}$ Post Graduate and Research Centre, Department of Chemistry, Maulana Azad College of Arts, Science and Commerce, Aurangabad, Maharashtra 431001, India. ${ }^{2}$ Department of Chemistry, S.K Gandhi College, Kada, Tal: Ashti, Dist: Beed, Maharashtra 414202, India.
Received: 13 May 2021 Accepted: 29 September 2021

Published online: 15 October 2021

\section{References}

1. AHFS drug information 2018. McEvoy GK, ed. Diltiazem hydrochloride. Bethesda, MD. American Society of Hospital Pharmacists. https://www. worldcat.org/title/ahfs-drug-information-2018/oclc/964919758 Accessed December 2018.

2. Amsterdam EA, Wenger NK, Brindis RG, Donal E, Ganiats TG, Holmes DR Jr Jaffe AS, Jneid H, Kelly RF, Kontos MC, Levine NG, Liebson PR, Mukherjee D, Peterson ED, Sabatine MS, Smalling RW, Zieman SJ (2014) AHA/ACC guideline for the management of patients with non-ST-elevation acute coronary syndromes: a report of the American College of Cardiology/ American Heart Association Task Force on Practice Guidelines. Circulation 130:344-426. https://doi.org/10.1161/CIR.0000000000000133

3. Fihn SD, Gardin JM, Abrams J, Berra K, Blankenship JC, Dallas AP, Douglas PS, Foody JM, Gerber TC, Hinderliter AL, King SB 3rd, Kligfield PD, Krumholz HM, Kwong RYK, Lim MJ, Linderbaum JA, Mack MJ, Munger MA, Prager RL, Sabik JF, Shaw LJ, Sikkema JD, Smith CR Jr, Smith SC Jr, Spertus JA, Williams SV (2012) ACF/AHA/ACP/AATS/PCNA/SCAI /STS guideline for the diagnosis and management of patients with Stable ischemic heart disease: a report of the American College of Cardiology Foundation/ American Heart Association task force on practice guidelines and the American College of Physicians, American Association for Thoracic Surgery, Preventive Cardiovascular Nurses Association, Society for Cardiovascular Angiography and Interventions and Society of Thoracic Surgeons. Circulation 126:354-471. https://doi.org/10.1161/CIR.0b013e3182776f83

4. International Conference on Harmonization (ICH) Q3A (R2): Impurities in new drug substance, October 2006.

5. International Conference on Harmonization (ICH) Q3B (R2): Impurities in new drug products, June 2006

6. FDA. Guidance for industry, analytical procedures and method validation for drug and biologics. U.S Department of Health and Human Services Food and Drug Administration, Centre for Drug Evaluation and Research (CDER), Centre for Biologics Evaluation and Research (CBER). July 2015.

7. Bakshi M, Singh S (2002) Development of validated stability indicating assay Methods-critical review. J Pharm Biomed Anal 28(6):1011-1040. https://doi.org/10.1016/s0731-7085(02)00047-x

8. International Conference on Harmonization (ICH) Q2 (R1): Validation of analytical procedures test and methodology, November 2005.

9. Epshtein N (2004) Validation of HPLC technique for pharmaceutical Analysis. Pharm Chem J 238(4):212-228

10. International Conference on Harmonization (ICH) Q1A (R2): stability testing of new drug substances and products. February 2003.

11. International Conference on Harmonization (ICH) Q1B, Stability testing; photostability testing of new drug substances and products, USA, 1996

12. Kamath BV, Shivram K, Shah AC (1993) Selective spectrophotometric determination of Diltiazem hydrochloride in tablets. J Pharm Biomed Anal 11(4):407-412. https://doi.org/10.1016/0731-7085(93)80037-2

13. Sastri CSP, Sreedhar K, Reddy MN, Sankar DG (1995) Visible spectrophotometric methods for the determination of Diltiazem hydrochloride. Indian J Pharm Sci 57(4):170-179

14. Akram M, El D (2005) Indirect spectrophotometric determination of Diltiazem hydrochloride in pure form and pharmaceutical formulations. Cent Eur J Chem 3(3):520-536. https://doi.org/10.2478/BF02479280

15. Gawande W, Chandewar AV (2010) Development and validation of spectroscopic method for estimation of Diltiazem hydrochloride in solid dosage form. J Pharm Res 3(12):3032-3033

16. Remon JP, Vergote GJ, Vervaet C, Haemers T, Verpoort F (2002) Nearinfrared FT-Raman spectroscopy as a rapid analytical tool for the determination of Diltiazem hydrochloride in tablets. Eur J Pharm Sci 16(1):63-67. https://doi.org/10.1016/s0928-0987(02)00058-1

17. Belanger GO, Leboeuf E, Langlois S (1987) Assay of diltiazem and deacetyldiltiazem by capillary gas chromatography. J Chromatogr 417:89-98. https://doi.org/10.1016/0378-4347(87)80094-4

18. Souza MAC, Pereira CEdO, Nogueira FHA, Pianetti GA (2017) Development and validation of a stability indicating HPLC method to determine 
Diltiazem hydrochloride in tablets and compounded capsules. Braz J Pharm Sci 53(3):1-8. https://doi.org/10.1590/s2175-97902017000300041

19. Bhagyashree R, Patil BOG, Paul BN, Ghodke AY, Mulaje SS (2014) Analytical method development and validation for the estimation of Diltiazem hydrochloride in bulk and pharmaceutical dosage form by RP-HPLC. Int J Drug Regul Aff 2(2):78-84. https://doi.org/10.22270/ijdra.v2i2.133

20. Wahab S, Joyce HR, Holloway G (2008) A stability-indicating HPLC procedure for determination of Diltiazem hydrochloride in extemporaneously compounded oral liquids. Pharm Technol Eur 20(3)

21. Arafat M (2014) Simple HPLC validated method for the determination of Diltiazem hydrochloride in human plasma. Int J Pharm Pharm Sci 6(9):213-216

22. Shah Y, Khanna S, Dighe VS (1990) High-performance liquid chromatographic determination of Diltiazem hydrochloride in tablets. Indian Drugs 27:363

23. Buur JL, Baynes RE, Yeatts JL, Davidson G, Defrancesco TC (2005) Analysis of diltiazem in Lipoderms transdermal gel using reversed-phase highperformance liquid chromatography applied to homogenization and stability study. J Pharm Biomed Anal 38(1):60-65. https://doi.org/10. 1016/j.jpba.2004.11.053

24. Sultana N, Arayne MS, Shafi N (2007) A validated method for the analysis of Diltiazem in raw materials and pharmaceutical formulations by RPHPLC. Pak J Pharm Sci 20(4):284-290

25. Shafi N, Siddiqui FA, Naseem H, Sher N, Zubair A, Hussain A, Zubair A, Hussain A, Sial AA, Baig MT (2013) An overview of analytical determination of diltiazem, cimetidine, ranitidine and famotidine by UV spectrophotometry and HPLC technique. J Chem. https://doi.org/10.1155/2013/ 184948

26. Bhatia MS, Kulkarni S, Jadhav SD, Khetmar SS (2012) Development of chromatographic technique for simultaneous estimation of lovastatin and Diltiazem hydrochloride. Mahidol Univ J Pharm Sci 39(3):17-23

27. Siddiqui FA, Sultana N, Arayne MS, Shafi N, Hussain CA (2010) Development of a RP-HPLC method for the simultaneous analysis of Diltiazem and statin. Application in pharmaceuticals and human serum. Anal Methods 2:1571-1576. https://doi.org/10.1039/C0AY00337A

28. Chaudhari BG, Patel J (2012) Development and validation of dual wavelength spectrophotometric method for simultaneous estimation of Rosuvastatin and Diltiazem in combined dosage form. Int J Pharm Res Sch 1(3):146-153

29. Coors C, Schulz HG, Stache F (1995) Development and validation of a bioanalytical method for the quantification of Diltiazem and Desacetyl
Diltiazem in plasma by capillary zone electrophoresis. J Chromatogr A 717:235-243. https://doi.org/10.1016/0021-9673(95)00622-4

30. Sultana N, Saeed AM, Shafi N, Siddiqui FA, Hussain A (2011) Development and validation of new assay method for the simultaneous analysis of diltiazem, metformin, pioglitazone and rosiglitazone by RP- HPLC and its applications in pharmaceuticals and human serum. J Chromatogr Sci 49:774-779. https://doi.org/10.1093/chrsci/49.10.774

31. Monograph of Diltiazem Hydrochloride, British Pharmacopoeia-2016

32. Monograph of Diltiazem hydrochloride, European pharmacopoeia 9.0. pp 2276-227

33. Monograph of diltiazem hydrochloride, United State pharmacopoeia. 2020; Page Information: USP43-NF38-398

34. Monograph of Diltiazem hydrochloride tablets, United State pharmacopoeia. 2020, Page Information: USP43-NF38-1406

35. Quaglia MG, Donati E, Fanali S, Bossù E, Montinaro A, Buiarelli F (2005) Analysis of Diltiazem and its related substances by HPLC and HPLC/MS. J Pharm Biomed Anal 37:695-701. https://doi.org/10.1016/j.jpba.2004.11. 050

36. Lacroix PM, Beaulieu N, Cyr TD, Lovering EG (1989) High performance liquid chromatography method for assay of Diltiazem hydrochloride and its related compounds in bulk drug and finished tablets. J Pharm Sci 78(3):243-246. https://doi.org/10.1002/jps.2600780315

37. Vivekanand A, Chatpalliwara PK, Porwala UN (2012) Validated gradient stability indicating HPLC method for determining Diltiazem Hydrochloride and related substances in bulk drug and novel tablet formulation. $J$ Pharm Anal 2(3):226-227. https://doi.org/10.1016/j.jpha.2012.01.003

38. Lee CR, Hubert M, Dau CNV Peter D, Krstulovic AM (2000) Determination of $\mathrm{N}, \mathrm{N}$-dimethylaminoethyl chloride and the dimethylaziridinium ion at sub-ppm levels in Diltiazem hydrochloride by LC-MS with electrospray ionisation. Analyst 125:1255-1259. https://doi.org/10.1039/b0009780

39. Grinstein MV, Billy J, John L, Van Antwerp J, Chapman D (1994) Detecting coeluted impurities by spectral comparison. LC GC 12(10):768-772

40. Young PM, Gorenstein MV (1994) Tryptic mapping by reversed phase HPLC with photodiode array detection incorporating the spectral contrast. Technique 12(11):832-838

\section{Publisher's Note}

Springer Nature remains neutral with regard to jurisdictional claims in published maps and institutional affiliations.

\section{Submit your manuscript to a SpringerOpen ${ }^{\circ}$ journal and benefit from:}

- Convenient online submission

- Rigorous peer review

- Open access: articles freely available online

- High visibility within the field

- Retaining the copyright to your article

Submit your next manuscript at $\boldsymbol{\nabla}$ springeropen.com 